\title{
Optimisation de l'induction de callogenèse à partir des embryons excisés de mandariniers (Citrus spp.)
}

\author{
Label Kawtar ${ }^{1 / 2}$, Handaji Najat ${ }^{1}$, Brhadda Najiba ${ }^{2}$, Arsalane Najat ${ }^{1}$, Gmira Najib ${ }^{2}$, Essalhi Elmustapha ${ }^{1,2}$, \\ Aderdour Tarik ${ }^{1 / 2}$, Benyahia Hamid1. \\ 1 : Institut National de La Recherche Agronomique, CRRAK, El Menzeh \\ 2 : Université Ibn Tofail, Faculté des Sciences, Laboratoire de Biodiversité et Ressources Naturelles, Kénitra (Maroc). \\ Email : nhandaji2002@yahoo.fr
}

Original submitted in on $25^{\text {th }}$ February 2015. Published online at www.m.elewa.org on $30^{\text {th }}$ May 2015 http://dx.doi.org/10.4314/jab.v89i1.4

\section{RÉSUMÉ}

Objectif : Actuellement, l'amélioration des agrumes vise entre autres la diversification variétale des petits agrumes sur des critères d'étalement de la production et d'amélioration des qualités organoleptiques et nutritionnelles, et une aptitude à la production de fruits de qualité. Ainsi l'augmentation de la variabilité génétique via la callogenèse est le principal objectif de cette étude. Dans ce sens, la détermination des conditions optimales d'induction de la callogenèse selon les milieux de culture et les génotypes constitue l'étape préliminaire de ce travail.

Méthodologie et résultats : la culture des cals a été initiée à partir des embryons excisés de six variétés de mandariniers (Anana, Lee, Murcott, Nadorcott, Temple, Ortanique) sur le milieu de base de Murashig et Tuker (MT). Différentes concentrations de régulateurs de croissance ont été testées afin d'obtenir le meilleur développement des cals: MT+ $1 \mathrm{mg} / \mathrm{l} 2.4 \mathrm{D}+0.5 \mathrm{mg} / \mathrm{l}$ Glutamine, MT+ $1 \mathrm{mg} / \mathrm{l} 2,4 \mathrm{D}+0,5 \mathrm{mg} / \mathrm{l}$ Asparagine, $M T+1 \mathrm{mg} / / 2,4 \mathrm{D}+0,5 \mathrm{mg} / \mathrm{lBAP}, \mathrm{MT}+1 \mathrm{mg} / \mathrm{l} 2,4 \mathrm{D}+0,5 \mathrm{mg} / \mathrm{l} \mathrm{ANA}, \mathrm{MT}+1 \mathrm{mg} / \mathrm{l} 2,4 \mathrm{D}+0,5 \mathrm{mg} / \mathrm{lkinétine}$. Résultats et discussion: Aucune réactivité n'a été observée sur le milieu de base MT sans régulateurs de croissance chez toutes les variétés. Ainsi, la concentration du régulateur de croissance a un effet significatif sur l'induction de cals, la croissance et la texture. La fréquence la plus élevée d'induction de cals a été observée sur le milieu de culture MT contenant les hormones de croissance 2-4 D/ BAP (1/0,5 mg/l). Les essais pratiqués ont révélé que les cals peuvent apparaître au bout de huit jours à l'obscurité. Les cals obtenus, sont friables, noduleux crémeux et blanchâtres chez les variétés Nadorcott, Temple, Ortanique et Murcott. Tandis que les variétés Anana et Lee représentent des cals brunâtre et compacts.

Conclusion et Application des résultats : Ces résultats mettent en évidence la grande aptitude de la callogenèse dans le milieu MT contenant $1 \mathrm{mg} / / 2-4 \mathrm{D}+1 \mathrm{mg} / \mathrm{l} \mathrm{BAP}$. Les cals friables obtenues seront repiqués dans d'autres milieux favorables pour l'induction d'embryogénèse somatique et puis la régénération des plantules. De plus, la maitrise de callogénèse pourrait servir le programme de fusion de protoplastes.

Mots Clés : Agrumes, mandarinier, callogenèse, variation somaclonale. 


\begin{abstract}
Objective: Currently, improving citrus aims at varietal diversification on based on production and improvement of organoleptic and nutritional qualities, and ability to produce quality fruit. Thus, the increase in the genetic variability via callogenesis is the main objective of this study. Determination of optimal conditions for induction of callus according to culture media and genotypes is preliminary stage of this work.

Methodology and Results: Culture of callus was initiated from embryos excised from six varieties of mandarin (Anana, Lee, Murcott, Nadorcott, Temple and Ortanique) on basal medium of Murashig Tuker (MT). Different concentrations of growth regulators were tested to obtain the best development of callus: MT + $1 \mathrm{mg} / \mathrm{I} 2.4 \mathrm{D}+$ $0.5 \mathrm{mg} /$ / glutamine, MT + $1 \mathrm{mg} / \mathrm{l}$ 2,4-D + $0.5 \mathrm{mg} / \mathrm{l}$ asparagine, MT + 1mg / 2,4-D + 0.5 mg / / BAP, MT + $1 \mathrm{mg}$ / / 2,4-D + 0.5 mg / I NAA, MT + 1mg / / 2,4-D + 0.5 mg / I kinetin,

Results and Discussion: No reaction was observed in the basal medium without growth regulators MT in all varieties. Thus, the concentration of the growth regulator has a significant effect on the induction of callus growth, and texture. The highest callus induction frequency was observed in the culture medium containing the MT growth hormones 2-4 D / BAP (1/ $0.5 \mathrm{mg} / \mathrm{l})$. Tests carried out showed that callus might appear after eight days in the dark. The calluses obtained are friable, nodular and creamy white in Nadorcott, Temple Ortanique and Murcott varieties, while cultivars Lee and Anana represented brownish compact callus.

Conclusion and Application of results: These results highlight the great ability of the callus in the MT medium containing $1 \mathrm{mg} / \mathrm{I}$ 2-4 D + $1 \mathrm{mg} /$ / BAP grown for eight days in the dark. Friable callus obtained will be planted in other medium favourable for somatic embryogenesis induction and seedling regeneration
\end{abstract}

Keywords : Citrus, mandarin, callogenesis, somaclonal variation.

\section{INTRODUCTION}

Au Maroc, le secteur agrumicole compte parmi les principales filières de production et joue un rôle important sur le plan socio-économique par la valeur ajoutée qu'elle génère et le nombre de journées de travail qu'elle offre annuellement. Sur un marché des fruits frais très concurrentiel, les petits agrumes, telles que les mandarines et les clémentines sont aujourd'hui l'un des secteurs les plus dynamiques de la production et des échanges mondiaux d'agrumes. De même, elles ont su gagner la préférence des consommateurs. Dans ce sens, la recherche de nouvelles variétés productives et de bonne qualité permettrait d'augmenter la popularité des consommateurs en proposant des produits sans pépins, faciles à peler et cultivables toute l'année. Parmi les méthodes d'amélioration génétique, l'induction in vitro de callogenèse est une étape fondamentale à maitriser pour mieux exploiter la fusion des protoplastes et la variation somaclonale. Elle était largement étudiée au cours de ces dernières années pour beaucoup de plantes d'intérêts économiques. Chez les citrus, l'embryogenèse somatique directe ou via la callogenèse offre de nombreuses perspectives pour la création variétale et la propagation des portegreffes (Vardi et al., 1990; Ollitrault et al., 1995 ; Carimi et al., 1998 et 1999 ; Khayri et al., 2001 ; Dutt et Grosser, 2009 et Grosser et al., 2009). Les potentialités calogènes et embryogènes apparaissent fortement différentes suivant le génotype, et dans une moindre mesure en fonction du stade de prélèvement. Cette différence de réactivité entre cultivars avait déjà été constatée par de nombreux auteurs (Kochba et al., 1972 ; 1976 ; Moore, 1985 ; Gmitter et Moore, 1986, Handaji et al., 2005). Elle est souvent corrélée au niveau de polyembryonie in vivo de cultivars et pourrait s'expliquer par des balances hormonales endogènes différentes (Moore, 1985). Chez les Citrus, la culture des cals a été obtenue à partir de nombreuses espèces, telles que grandis, aurantifolia, medica, limon, madirensis, paradissi, reticulata (Sabharwal, 1963; Murashig and Tucker, 1963 ; Chaturvedi et Mitra, 1915 ; Moore, 1985 ; Gill, 1992 ; Gill et al., 
1994 ; Tao et al., 2002). Le développement des cals embryogènes est le point de départ pour l'isolation des protoplastes et la régénération des plantules (Vardi et al,1982; Kobayashi et al,1988 et Starrantino et al., 1992). De même, la recherche de la variation somaclonale est exploitée sur les agrumes, pour sélectionner des porte greffes résistants et tolérants à la salinité (Beloualy et Bouharmont, 1992; Bouharmont, 1996 ; Bougarfaoui, 1987; Abousalim et al, 2002, et Beniken et al 2013). Aussi, l'induction des cals a été initiée à partir des ovules des mandariniers (Handaji et al., 2005, Ollitrault et al 1992, B. Singh1 et al 2006,); des embryons excisés des porte greffes d'agrumes (Benyahia et al., 2012, Ramdan et al, 2014, El yacoubi et al 2010; Nafees Altaf et al 2009), des fragments des feuilles (Nafess Altaf et al,

\section{MATERIEL ET METHODES}

Matériel végétal : L'étude a porté sur les graines issues de fruits mûrs de sept mandarines (Tableau1). Les échantillons sont récoltés au niveau de la collection d'agrumes de l'INRA El Menzeh. Cette récolte s'est effectuée sur une période de quatre mois courant Novembre - Février. L'expérimentation de la culture in
2009). D'après Lutz (1985) et Nozeran (1985), l'initiation de la callogenèse semble être due au bouleversement du comportement des explants. La présente étude vise à déterminer les conditions optimales de callogenèse à partir d'embryons excisés de six variétés de mandariniers (Nadorcott, Ortanique, Lee, Murcott, Temple). La présente étude est menée dans le cadre du programme d'amélioration des Variétés d'agrumes lancé par I'INRA Maroc dont l'objectifs est de Déterminer le milieu favorable pour l'induction des cals des différentes variétés de mandariniers (Nadorcott, Ortanique, Lee, Murcott, Temple) à partir des embryons excisés, ce qui va nous permettre de Comparer la capacité d'induction de callogenèse ; selon différentes combinaisons hormonales ainsi selon la diversité variétal.

vitro a été réalisée dans le laboratoire de l'unité de recherche d'amélioration et conservation des ressources phytogénétique de l'INRA Kenitra. L'explant, représenté par les embryons excisés, est prélevéà partir des graines matures de différentes variétés.

Tableau 1 : Liste des variétés de mandarinier utilisées

\begin{tabular}{|l|l|l|l|}
\cline { 2 - 4 } \multicolumn{1}{c|}{} & \multicolumn{1}{c|}{ Nom } & \multicolumn{1}{c|}{ Variétés de mandarinier } \\
\hline \multirow{4}{*}{ Tardives } & Nadorcott (Afourer) & Murcott Honney $X$ unknown (2) & \multicolumn{1}{c|}{ Intérêt } \\
& Ortanique & C. sinensis X tangerine (3) & Commercial \\
& Anana & C. reticulata Blanco (3) & Ressources génétiques \\
& Murcott (Tangor) & C. reticulata X C. Sinensis (1) & Ressources génétiques \\
\hline Saisons & Temple (Tangor) & C. reticulata X C. sinensis & Ressources génétiques \\
& Lee & C. paradisi X tangerine (3) & Ressources génétiques \\
\hline
\end{tabular}

Légende : (1): Gogorcena et al. (1990); (2): Handaji et al. (2004) ; (3): EGID (2003)

Désinfection et préparation de l'explant : Les graines ont subi un trempage rapide dans l'éthanol $70 \%(\mathrm{v} / \mathrm{v})$ pendant $5 \mathrm{~min}$, suivi de l'immersion pendant $10 \mathrm{~min}$ dans l'hypochlorite de calcium $10 \%(\mathrm{~m} / \mathrm{v})$. Ensuite les graines subissent trois rinçage, successive dans l'eau distillée stérile, les graines ont été débarrassées de leurs téguments, A l'aide d'une pince et d'un scalpel l'embryon a été isolé. Toutes ces opérations ont été réalisées sous une hotte à flux laminaire.

Préparation et incubation des milieux de culture : Pour toutes les expériences réalisées, le milieu de base est celui de (Murashige et Tucker, 1969). Cinq compositions ont été testées dont le milieu témoin (M0) est dépourvu d'hormone, alors que les autres milieux contenant tous $1 \mathrm{mg} / \mathrm{L}$ de l'auxine 2,4-D (Acide 2,4Dichlorophénoxy) acétique) ou $\mathrm{C}_{8} \mathrm{H}_{6} \mathrm{Cl}_{2} \mathrm{O}_{3}$, se diffèrent par l'addition d'une cytokénine BAP (6-benzylaminopurine) et la Kinétine ; de l'auxine ANA (Acide Naphtalène ...) ou des acides aminés non polaires (Glutamine et asparagine) (Tableau 2). Tous les milieux utilisés dans cette étude ont été stérilisés à autoclavage à $121^{\circ} \mathrm{C}$, sous une pression de 1 bar pendant 30 minutes. Puis, ont été 
répartis sous la hotte en raison de $25 \mathrm{ml} /$ boîte de Pétri. Pour la culture et la conservation des cals, ils ont été repiqués une fois tous les 15 jours dans le même milieu de culture.

Tableau2 : Composition des milieux de culture testés

\begin{tabular}{|c|c|c|}
\hline Milieu & Concentration & \\
\hline MO & MT & \\
\hline M1 & $M T+1 m g / / 2,4 D+$ & 0,5mg/l Glutamine \\
\hline M2 & $M T+1 \mathrm{mg} / \mathrm{l} 2,4 \mathrm{D}+$ & 0,5mg/l Asparagine \\
\hline M3 & $M T+1 m g / / 2,4 D+$ & $0,5 \mathrm{mg} / \mathrm{BAP}$ \\
\hline M4 & $M T+1 m g / l 2,4 D+$ & $0,5 \mathrm{mg} / \mathrm{l}$ ANA \\
\hline M5 & $M T+1 m g / / 2,4 D+$ & 0,5mg/l kinétine \\
\hline
\end{tabular}

MT : Murashige et Tucker

Mise en culture: Sous la hotte à flux laminaire, les embryons excisés ont été placés dans les boites de pétri à raison de quatre explants par boite. Les boîtes de Pétri ont été mises dans une chambre de culture obscure avec une température de $25 \pm 2^{\circ} \mathrm{C}$, et une hygrométrie de 70

\section{RÉSULTATS ET DISCUSSION}

Effet de la composition du milieu de culture: L'initiation des cals à partir des embryons excisés de différentes variétés de mandarinier a été favorisée par la présence d'hormones de croissance dans le milieu. Tandis que le milieu de culture dépourvu d'hormones (M0) se solde par une absence totale d'activité cellulaire. Le taux de callogenèse a varié de $24 \%$ à $72 \%$ selon les cinq milieux de culture. Le milieu M 3 contenant le $2.4 \mathrm{D}$ et la BAP à des concentrations de 1 et $0,5 \mathrm{mg} / \mathrm{l}$ nous a permis d'obtenir un taux de callogenèse de $72,92 \%$, ainsi le milieu M1 additionné par la Glutamine $(0.5 \mathrm{mg} / \mathrm{L})$ a permis une induction de cal de $46.25 \%$. Alors que; le milieu M5 contenant la kenitine $(0.5 \mathrm{mg} / \mathrm{L})$ a donné un taux de callogenèse relativement faible $(24.72 \%)$. L'analyse de la variance a montré que l'effet de milieu de culture est hautement significatif (Tableau 3). La comparaison des moyennes des pourcentages d'induction des cals a révélé quatre groupes qui diffèrent significativement :

Groupe 1: contient le milieu M3 dont le pourcentage d'induction de cals est $72.92 \%$

Groupe 2: contient le milieu M1 qui a permis un pourcentage de callogenèse de $46.25 \%$

Groupe 3: contient le milieu M2 et M4 ont permis respectivement des pourcentages d'induction de cals de $32.61 \%$ et $35.22 \%$.

Groupe 4 : contient le milieu M5 dont le pourcentage d'induction de cals est $24.72 \%$.
$\%$ (humidité relative). Pour chaque combinaison hormonale (génotype/milieu) six répétitions ont été réalisées. Le taux d'induction des cals et l'intensité de prolifération des cals ont été évalués après quatre semaines de culture.

L'association de 2.4D et la glutamine M1 a favorisé un taux de callogenèse de $46.25 \%$, II a été rapporté que l'addition de glutamine au milieu contenant les cytokinines ou auxines a augmenté la capacité de régénération de cals de blé âgés de 6 à $10 \%$ et une fréquence d'induction de pousses de 55\% (Shrivastava, 2001). Aussi ; Drira et Benbadis (1975) ont confirmé que l'addition de la glutamine est nécessaire pour la production de cals a partir de la mise en culture des anthères de Citrus limon. Dans des études antérieurs, il a été constaté que l'application exogène d'un acide aminé spécifique, notamment l'asparagine, favorise le processus de l'embryogenèse somatique et la régénération. L'utilité de l'asparagine peut être considéré à fournir un approvisionnement en azote organique associée à la culture et de l'embryogenèse in vitro. Cependant différentes sources d'azote organiques, y compris les acides aminés indiquent la nécessité d'acides aminés pour des événements spécifiques au cours de la morphogenèse (SARKER et al, 2007). Ceci confirme les résultats obtenus du milieu M2 contenant de l'asparagine et qui a engendré $67.38 \%$ de cal ayant présentés une organogénèse. En revanche, les milieux M4 et M5 contenant respectivement l'asparagine, I'ANA et la kinétine ont donné le meilleur taux d'organogénèse de $64.77 \%$ et de $75.27 \%$ respectivement. Une diminution de la fréquence d'induction de cals a été constatée avec l'apport 2.4D et ANA, Ceci a été conforme aux études antérieures (Pena et al. 1995; Kaneyoshi et al. 1994; 
Chakraborty et Goswami, 1999; Normah et al. 1997; Usman et al. 2005; Rani et al. 2004). Par ailleurs, la kinetine a favorisé l'induction des cals mais à partir de la mise en culture in vitro des ovules du mandarinier (Handaji et al , 2005, Singh et al 2006). La nature, l'âge, la position, l'orientation des explants, leurs besoins spécifiques en éléments nutritifs et leurs teneurs endogènes en hormones influencent la réponse à la callogenèse (Mathews, 1987).

Tableau 3 : Pourcentage de callogenèse selon les milieux de culture utilisés

\begin{tabular}{|c|c|c|c|c|c|c|}
\hline \multirow{3}{*}{ Variétés } & \multicolumn{6}{|c|}{ Pourcentage de callogenèse } \\
\hline & \multicolumn{6}{|c|}{ Milieux } \\
\hline & M0 & M1 & M2 & M3 & M4 & M5 \\
\hline Nadorcott & $0 \mathrm{a}$ & $41.67 \mathrm{~b}$ & $18.75 \mathrm{c}$ & $100 a$ & $18.75 b$ & --.-- \\
\hline Anana & $0 \mathrm{a}$ & $32.14 b$ & $24.62 b c$ & $25.00 \mathrm{a}$ & $18.75 b$ & $11.25 b$ \\
\hline Lee & $0 \mathrm{a}$ & $50.00 \mathrm{~b}$ & $42.50 \mathrm{~b}$ & $12.5 b$ & $91.67 a$ & $37.50 \mathrm{a}$ \\
\hline Murcott & $0 \mathrm{a}$ & $53.33 b$ & $83.75 a$ & $95.00 \mathrm{a}$ & $35.50 \mathrm{~b}$ & $25.00 \mathrm{ab}$ \\
\hline Ortanique & $0 \mathrm{a}$ & $35.00 \mathrm{~b}$ & $16.68 \mathrm{c}$ & $91.66 \mathrm{a}$ & $16.67 \mathrm{~b}$ & 33.33ab \\
\hline Temple & $0 \mathrm{a}$ & $91.67 a$ & $17.86 \mathrm{c}$ & $95.00 \mathrm{a}$ & $37.50 \mathrm{~b}$ & 16.67ab \\
\hline Moyenne & $0 \mathrm{a}$ & 46.25 & 32.61 & 72.91 & 35.22 & 24.72 \\
\hline
\end{tabular}

Les chiffres de la même colonne suivis des même lettres ne différent pas significativement au seuil 5\%(Test Duncan)

Effet Variété : D'après les résultats, on constate que l'aptitude à la callogenèse diffère non seulement en fonction des milieux de culture utilisés mais aussi selon les variétés utilisées. En effet, la variété Nadorcott (Afourer) est caractérisée par un taux de callogenèse très élevé $(100 \%)$, suivi par la variété Temple et Murcott $(95 \%)$, et Ortanique $(93,66 \%)$ dans le milieu M3. Par contre, les mandarines Lee et Anana ont présenté des taux de callogenèse faibles de $12.5 \%$ et $25 \%$ respectivement (Figure 1). En revanche, elles ont donné le taux d'organogénèse le plus élevé. Par ailleurs, le milieu M4 a favorisé un taux d'organogénèse de $83 \%$ chez la variété Ortanique. II est important de signaler l'existence d'un effet hautement significative du facteur "variété » sur le pourcentage d'induction de la callogenèse. Le milieu M3 a favorisé l'optimisation de l'induction de callogenèse chez toutes les variétés de mandarinier à l'exception des deux variétés Anana et Lee. Cette différence de réactivité entre cultivars a aussi été constatée par de nombreux auteurs (Kochba et al. 1972; Gmitter et Moore, 1986 et Bugam et al. 2003, Handaji et al., 2005). Elle est souvent corrélée au niveau de la polyembryonie in vivo des cultivars et pourrait s'expliquer par des balances hormonales endogènes différentes (Gmitter et Moore, 1986)

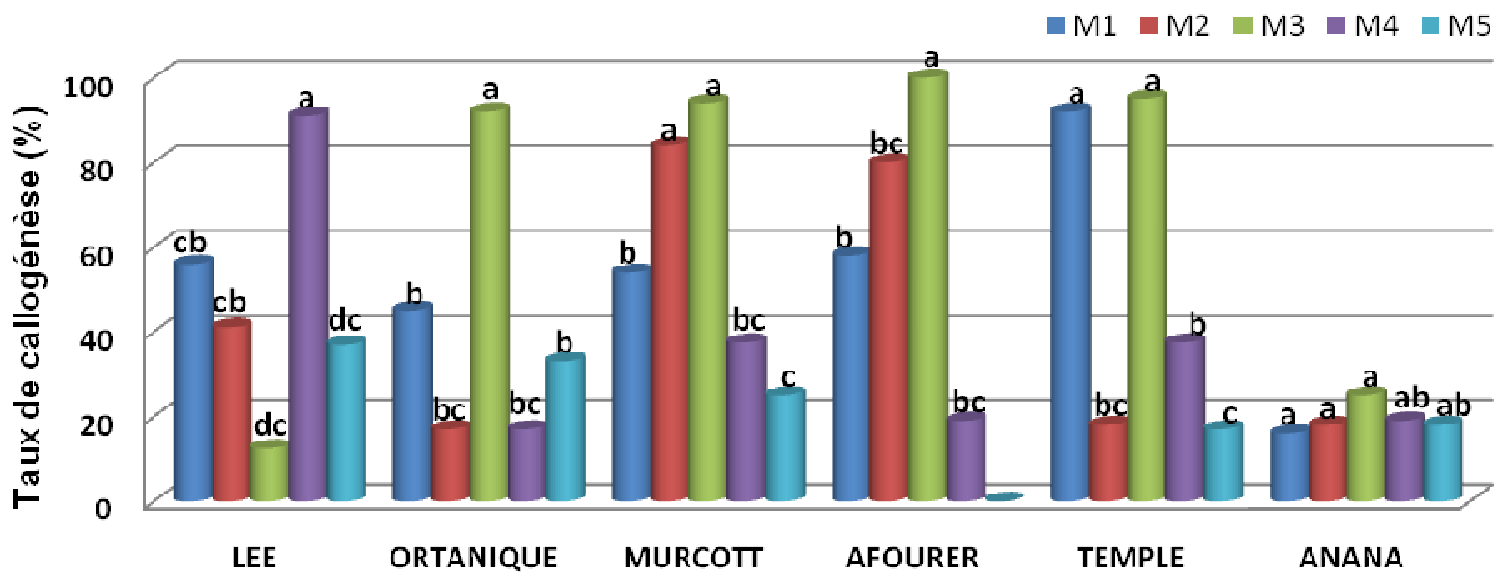

Figure 1 : Taux de callogenèse selon les variétés de mandariniers et les milieux utilisés. (Les variétés suivis de la même lettres ne différent pas significativement au seuil 5\% (Test Duncan). 
Effet des combinaisons hormonales sur la morphologie des cals : Selon les milieux et les variétés utilisées, les cals issues de graines excisées diffèrent par la couleur et la texture (Figure 2). Ainsi, l'aspect des cals change en fonction du milieu de culture et des conditions d'incubation (Tableau. 4). Le milieu M3 contenant le 2.4 D et la BAP a donné des cals blanchâtres, friables et embryogènes pour toutes les variétés étudiées à l'exception des variétés Lee et Anana qui ont donné des cals Brunâtres et compacts. Le milieu M5 (2.4D+ kinétine) a donné des cals brunâtres et compacts chez toutes les variétés de mandarinier, tandis que le milieu M1 a donné des cals friables et blanchâtres chez les variétés Nadorcott et Temple. Par contre, les milieux de culture contenant ANA, la kinétine et l'Asparagine ont favorisé le déclenchement de la germination et l'apparition de la racine chez les différentes variétés (Figure 3 ).
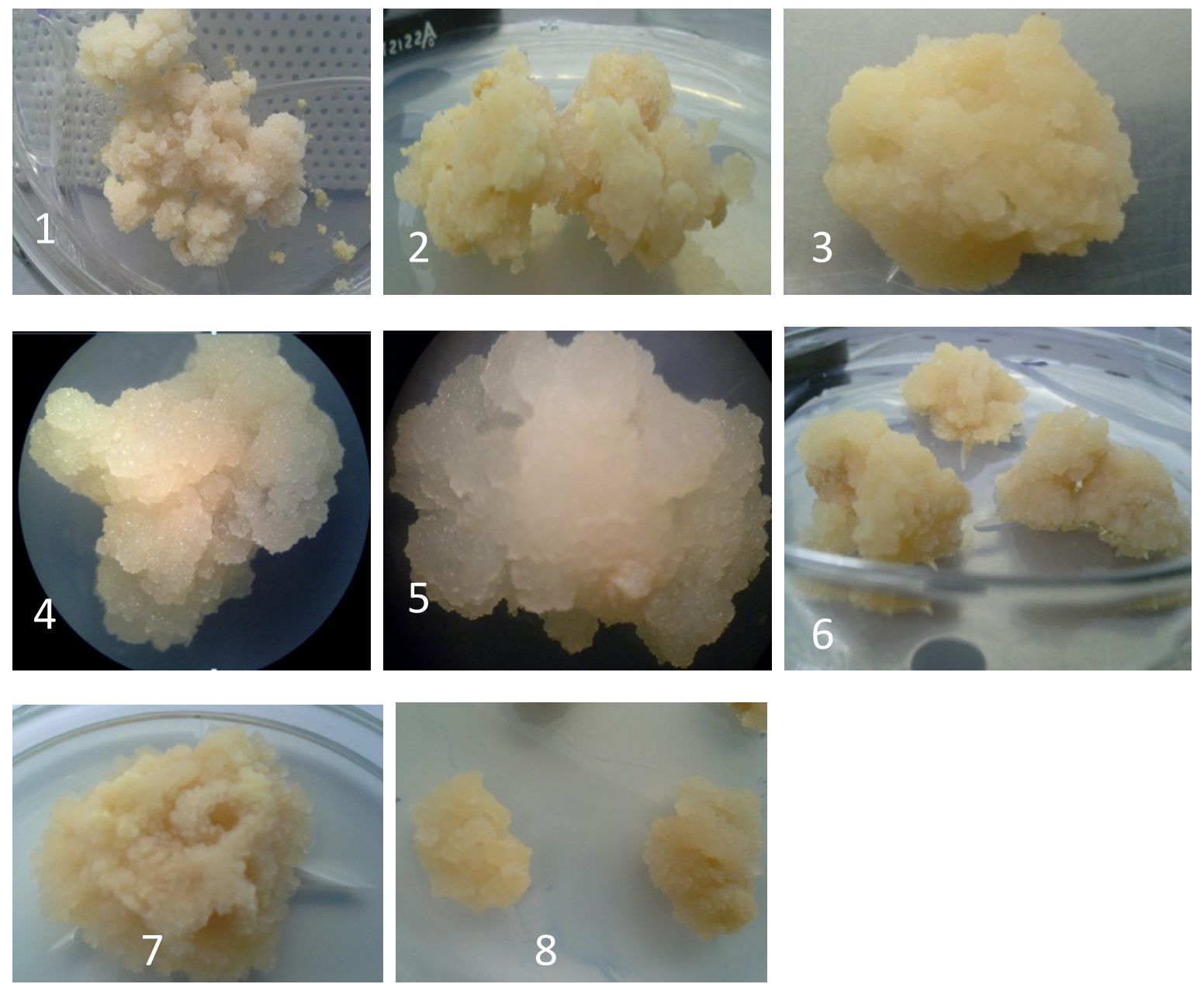

Figure 2 : Cals obtenus à partir des embryons excisés dans le milieu $M 3$ de différentes variétés de mandariniers : 1,2: Nadorcott, 3,4: Murcott 5,6: Temple, 7,8: Ortanique

Les auxines, cytokinines et acides aminés ont présenté des effets différents en terme de pourcentage d'induction de callogenèse, d'organogénèse et de texture de cal, selon les différentes variétés de mandariniers. L'association des auxines et des cytokinines présentent un effet synergique et complémentaire, les cytokinines stimulent la sensibilité des tissus en particuliers les cellules compétentes pendant la phase de callogenèse (Ramdan et al 2014), cet effet a été aussi démontré chez des espèces ligneuses telles que les pistaches (Hafdi et al, 2000), et le palmier dattier (Asemota et al, 2007). Huang et al, (2002), Savita et al, (2010). 
Tableau 4 : Couleur et texture des cals selon les variétés de mandariniers étudiés

\begin{tabular}{|c|c|c|c|c|c|c|}
\hline $\begin{array}{c}\text { Variétés/ } \\
\text { Milieu }\end{array}$ & Lee & Anana & Ortanique & Nadorcott & Temple & Murcott \\
\hline M1 & Blanchâtre & Brunâtre & Blanchâtre & Blanchâtre & Blanchâtre & Brunâtre \\
\cline { 5 - 7 } & Compact & Compact & Compact & Friable & Friable & Compact \\
\hline M2 & Blanchâtre & Brunâtre & Brunâtre & Brunâtre & Blanchâtre & Brunâtre \\
& Compact & Compact & Compact & Compact & Compact & Friable \\
\hline M3 & Brunâtre & Brunâtre & Blanchâtre & Blanchâtre & Blanchâtre & Blanchâtre \\
& Compact & Compact & Friable & Friable & Friable & Friable \\
\hline M4 & Blanchâtre & Brunâtre & Pas de & Brunâtre & Brunâtre & Brunâtre \\
& Friable & Compact & résultats & Compact & Compact & Compact \\
\hline M5 & Brunâtre & Brunâtre & Brunâtre & & Brunâtre & Brunâtre \\
& Compact & Compact & Compact & & Compact & Compact \\
\hline
\end{tabular}

Le milieu M0 n'a donné aucune réaction

Ont rapporté aussi l'effet des auxines sur l'induction des cals chez les agrumes. De nombreux rapports indiquent que la source d'azote organique comme les acides aminés au lieu de la source inorganique comme les nitrates ou les sulfate d'ammonium, peut améliorer la prolifération cellulaire et la régénération des génotypes spécifiques (Vasudevan et al, 2004; Asad et al, 2009.).
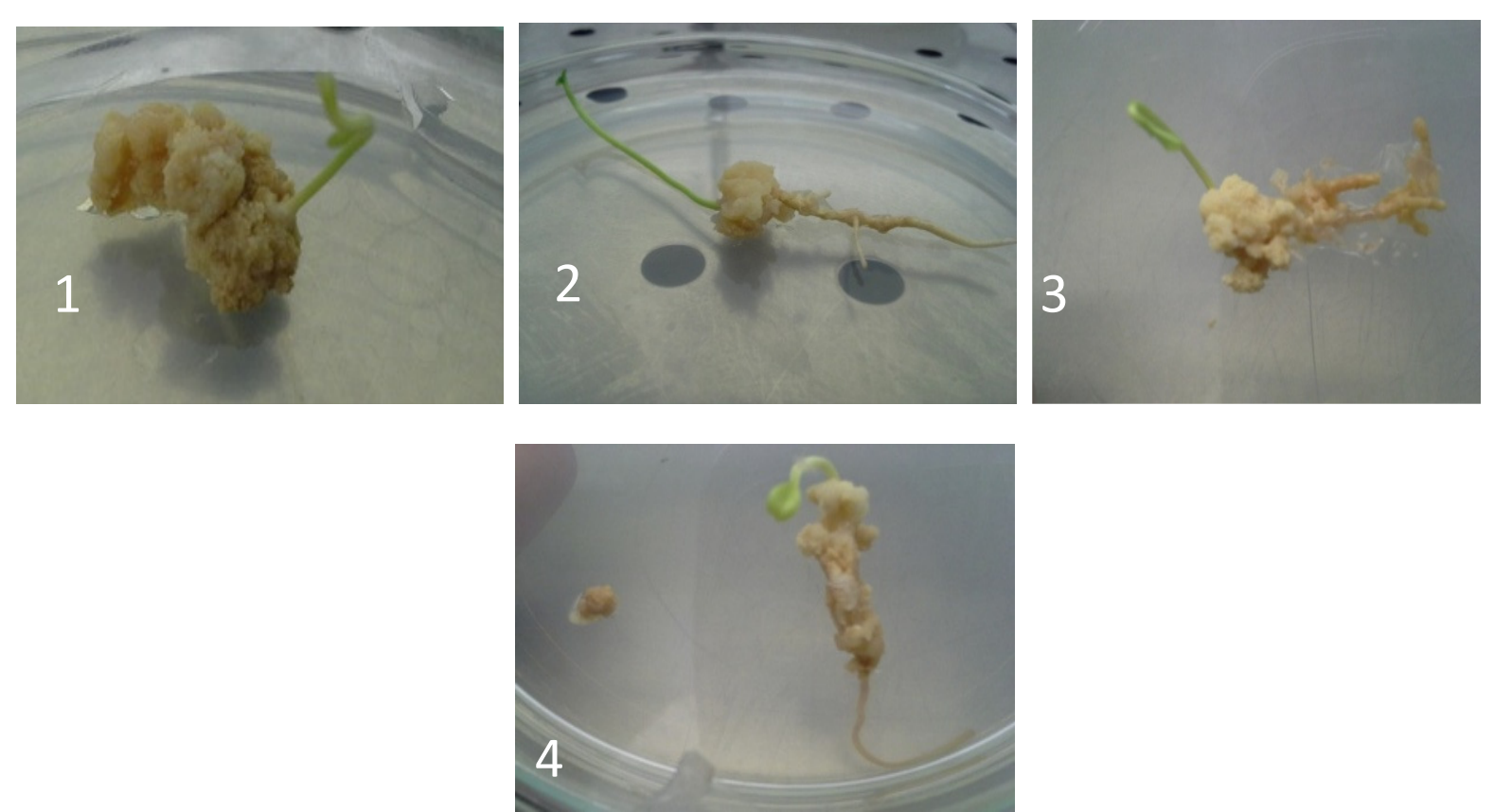

Figure 3 : Organogénèse des embryons excisés dans le milieu M2 de différentes variétés de mandariniers (1:Nadorcott, $2:$ Murcott, $3:$ Temple, 4 : Lee)

\section{CONCLUSION}

La variabilité de la callogenèse vis-à-vis des explants dépend du type et de la concentration des hormones de croissance utilisées et aussi du génotype de la variété. Ces résultats mettent en évidence la grande aptitude de la callogenèse dans le milieu MT contenant $1 \mathrm{mg} / \mathrm{l} 2-4 \mathrm{D}$ + $1 \mathrm{mg} / \mathrm{l} \mathrm{BAP}$. En effet, l'utilisation de la cytokinine combinés avec l'auxine semble être importante pour l'induction et la prolifération des cals. Les cals friables 
obtenues seront repiqués dans d'autres milieux favorables pour l'induction d'embryogénèse somatique et puis la régénération des plantules. . Par ailleurs, la mandarine Nadorcott, en plus de son intérêt commercial,

\section{RÉFÉRENCES BIBLIOGRAPHIQUES}

Abousalim A, Nour-Eddine E, Othmane R et Abdelatif, 2002. Sélection in vitro de lignées de cals de porte-greffes d'agrumes tolérant la salinité. Actes Inst. Agron. (Maroc), vol 22 (4):189-191.

Ahmed J, Nedra E, Claire K, Jacques D, 2002. Morphological and hormonal characterization of strawberry in vitro plants raised through axillary or stipular adventitious shooting. Plant Growth Regul 38, 273-278.

Amzad H, Kunihiko K, Mineo M, Kazuhiro N, 2003. Somaclonal variation of regenerated plants in chili pepper (Capsicum annuum L.). Euphytica 130, 233-239.

Asemota O, Eke CR. and Odewale JO, 2007. Date palm (Phoenix dactylifera L.) in vitro morphogenesis in response to growth regulators, sucrose and nitrogen. Afr. J.Biotechnol., 6: 2353-2357.

Asad S, Muhammad A, mansoor S, Zafar Y,2009. Effect of various amino acids on shoot regeneration of sugarcane (Sacchrum officinalis L.). Afr. J. Biotechnol. 8(7):1214-1218.

Beloualy N \& Bouharmont J,1992. NaCl tolerant plants of Poncirus trifoliata regenerated from tolerant cell lines. Theor appl Genet 83: 509-514.

Beloualy $N$,1991. Plant regeneration from callus of three Citrus rootstocks. Plant Cell Tissue Org Cult 24: 29-34.

Benyahia H, Chetto O, Dominique D, Yann F, 2012. Mise au point des conditions de calogenèse, caulogenèse et rhizogenèse chez les portegreffes d'agrumes à partir d'épicotyle: cas du citrange Troyer. Journal of Applied Biosciences 60: 4375- 4387.

Bipasha C, Goswami B.C, 1999. Plantlet regeneration from long-term callus cultures of Citrus acida and the uniformity of regenerated plants. Scientia Horticulturae 82, 159-169.

Bougarfaoui M, 1987. Variabilité induite et amélioration de la tolérance à la salinité chez les agrumes. Mémoire, Option Horticulture, I.A.V. Hassan II, Rabat.

Bouharmont J, 1996. Variation et sélection in vitro, tolérance à la salinité, vitro variation, potentialités s'est révélée très intéressante pour la grande capacité de produire des cals friables. La maitrise de callogénèse pourrait servir le programme de fusion de protoplastes.

nouvelles et sélection in vitro. Biotechnologies Végétales 96: 74-79.

Bugam F, Amin MN, Islam S, Azard MAK. and Rehman MM, 2003. in vitro plant regeneration from cotyledon derived callus of three varieties Pummelo (C. grandis). Online Journal of biological Science 3 (8) :155-759.

Beniken L, Omari F, Dahan R, Van Damme P, Benkirane $\mathrm{R}$, Benyahia $\mathrm{H}, 2$ 2013. Évaluation de l'effet du stress hydrique et du porte greffe sur la clémentine Citrus reticulata Swingle var. Sidi Aissa. Journal of Applied Biosciences 71:56925704.

Carimi F, Tortorici MC, Crescimanno FG. and Guilio F, 1998. Somatic embryogenesis and plant regeneration from undeveloped ovules and stigmat/ style explants of sweet orange navel group. Plant cell tissue and organ culture 54: 183-189.

Carimi FF, De Pasqule F. and Crescimanno FG, 1999. Somatic embryogenesis and plant regeneration from pistil thin cell layers of citrus. Plant cell reports 18:935-940.

Chakraborty B, Goswami BC, 1999. Plantlet regeneration from longterm callus cultures of Citrus acida Roxb. and the uniformity of regenerated plants. Sci Hortic 82: 159-169.

Chakravarty B, Goswamy BC, 1999. Plantlet regeneration from long-term callus cultures of Citrus acida Roxb. and uniformity of regenerated plants. - Scientia Hortic. 82(1-2): 159-169.

Chaturvedi HC. and Mitra GC, 1915. A shift in morphologic pattern in citrus callus tissu during prolonged culture. Ann Bot 39: 683-687.

Chatterjee B, Gupta PD, 1998. Induction of somaclonal variation by tissue culture and cytogenetic analysis in Oryza sativa L. Biol. Plant 40 (1), 2532.

Das A, Paul AK, Chaudhary S, 2000. Micropropagation of sweet orange (Citrus sinenesis osbeck) for the development of nucellar seedlings. Ind J Exp Biol 38: 269-272. 
Drira N. and Benbadis A, 1975. Analyse, par culture d'antheres in vitro, des potentialites androgenetiques de deux espèces de Citrus (Citrus medica L. et Citrus).

Duran-Vila N, Ortega V, Navarro L, 1989. Morphogenesis and tissue culture of three Citrus species. Plant Cell, Tissue Organ Cult 16(2), 123-13.

Dutt M, Grosser JW, 2009. Evaluation of parameters affecting Agrobacterium mediated transformation of Citrus. Plant Cell Tissue Organ Cult 98, 331340.

Einset WJ, Cheng A, Elhag H, 1980. Citrus tissue culture: regulation of stylar abscission in excised pistils. Can J Bot 58:1257-1261.

El yacoubi H, Zidane L, Douira A, Rochdi Atmane, 2010. Effets de deux phytohormones et de l'hydrlysat de caséine sur la callogenèse de trois porte-greffes d'agrumes. Bull. Soc. Pharm. Bordeaux, 2010, 149, 7-16.

Gill MIS, 1992. Studies on somatic cell and protoplast culture in mandarin. $\mathrm{PhD}$ thesis. Punjab Agricultural university Ludhiana.

Gill MIS, Singh, Z, Dhillon BS and Gosal SS,1994. Somatic embryogenesis and Plantlet regeneration on callus derived from seedling explants of kinnow mandarin. Journal Hort Science 69: 231236.

Gmitter FG. et Moore GA, 1986. Plant regeneration from undeveloped ovules and embryonic callus of Citrus: Embryon production, germination and plant survival. Plant. Cell. Tissue and Organ Culture. 6: 139-147.

Gmitter FGJ, Ling XB, Deng XX ,1990. Induction of triploid Citrus plants from endosperm calli in vitro. Theor Appl Genet 80:785-790..

Grosser JW, Gmitter Jr FG, 2009. In vitro breeding provides new and unique

Hafdi A, Abousalim A, 2000, Effets de BAP combinéau 2,4-D et du prétraitement des explants avec BAP et 2,4-D sur l'induction et le développement des cals de Pistachier. ActesInst Agron Vet (Maroc), 20 (3), 163-167.

Handaji N, Arsalane N, Lamarti A, Dambier D, Benyahia H, Miaghizo H, Cheikh OY, Ollitrault P, 2005. Induction de l'embryogenèse somatique et régénération des plantules chez les mandariniers (Citrus reticulata L). El Awamia; 114: 2 (2): 109118.
Huang T, Peng S, Dong G, Zhang LLiG, 2002, Plant regeneration from leaf-derived callus in Citrus grandis: Effects of auxins in callus induction medium - Plant cell, Tissue and organ culture, vol. $69, n^{\circ} 2$, pp. 141-146.

Kaneyoshi J, Kobayashi S, Nakamura Y, Shigemoto N, Doi Y,1994.A simple and efficient gene transfer system to trifoliate orange (Ponicirus trifoliata Raf.). Plant Cell Rep 13:541-545.

Kaushal K, Nath AK, Kaundal P, Sharma DR, 2004. Studies on somaclonal variation in strawberry (Fragaria_ananassa duch.) cultivars. Acta Hortic. 662: 269-275.

Khayri JM, Albahray M, 2001 in vitro micro propagation of citrus aurantifolia. Current Science, 81: 1241246.

Kobayashi S, Ohgawara T, Ohgawara E, Oiyama I, Ishii S,1988. A Somatic Hybrid Plant Obtained By Protoplast Fusion Between Navel Orange (C. Sinensis) and Satsuma mandarin. Plant Cell Tissus. Org. Cult 14: 63-69.

Kochba J, Spiegel Roy P, Safreu H,1972. Adventives Plant From Ovules And Nucelli. In Citrus' Planta Berl 106: 237-245.

Kochba J, Spiegel-Roy Y P, 1976. The Use Of Citrus Tissue Culture For Mutation Breeding: Effects Of Plant Growth Substances And Gamma Irradiation On Embryogenesis.In Improvement of Vegetatively Propagated Plant And Tree Crops Through Induced Mutation. Wageningen. laea. Vienna. 83-92.

Kochba J, Spiegel Roy P and Safreu H,1972. Adventive plant from ovules and nucelli in citrus. Planta berl 106,237-245.

Lutz A, 1985. L'expression de la variabilité morphologique après régénération dans les cultures de tissus et de cellules, Bulletin Scientifique Botanique 132, France, pp.35-50.

Manjula SM, Kuruvinashetti MS, Chandrashekhar $\mathrm{CH}, 2000$. Regeneration, establishment and evaluation of somaclones in Sorghum bicolor (L.) Moench. Euphytica 115, 173-180.

Mathews $\mathrm{H}, 1987$. Morphogenetic responses from in vitro cultured seedling explants of mung bean (Vigna radiata L. Wilczek), Plant Cell, Tissue Org. Cult (11) 233-240.

Moore GA ,1985.Factors Affecting In Vitro Embryogenesis from Undeveloped Ovules of 
Mature Citrus Fruit. J. Amer. Soc. Hort. Sci 110 (1): $66-70$.

Moore, 1985. Factors affecting in vitro embryogenesis from undeveloped ovules of mature Citrus fruit. J. Amer. Soc. Hort.; Sci 110(1), 66-70.

Munazir M, Qureshi R, Ali GM, Rashid U, Noor S, Mehmood K, Ali S, Arshad M ,2010. Primary callus induction, somatic embryogenesis and regeneration studies in elite wheat varieties from Pakistan. Pak. J. Bot 42(6): 3957-3965.

Murashige T. and Tucker DPH, 1969. Growth factor requirements of citrus tissue culture. Proceeding first international citrus symposium. Vol 3'.

Nafees A, Abdul rehmen K, LIAQAT A, INKISAR AB, 2009. In vitro culture of kinnow explants. Pak. J. Bot., 41(2): 597-602.

Normah MN, Hamidoh S, Ghani FD ,1997. Micropropagation of Citrus halimii - an endangered species of South-east Asia. Plant Cell Tissue Org Cult 50:225-227.

Nozeran R, 1985. «L'expression de la variabilité dans les cultures d'organes » Actualités Botaniques, Paris, pp.11-21.

Ollitrault $P$, Luro F, Allent $V$ et Dambier D,1995. Diversification des mandariniers: apport des biotechnologies pour la création de cultivars triploïdes aspermes. Symposium sur les mandarines. San Giuliano. France, 5-11.

Ollitrault $\mathrm{P}$, Ollitrault F, Cabasson C, 1992. Fruits, 47 (spéc. Agrumes) : n. spéc. Induction of embryogenetic citrus calli through ovule culture : isozyme detection of the origin of embryos.

Pena L, Cervera M, Juarez J, Navarro A, Pina JA, DuranVilla N, Navarro L, 1995. Agrobacterium-mediated transformation of sweet orange and regeneration of transgenic plants. Plant Cell Rep 14:616-619.

Radhakrishnan R, and Ranjithakumari BD, 2007. Callus induction and plant regeneration of Indian soybean (Glycine max (L.) Merr. Cv. CO3) via half seed explant culture, J of Agric Tech 3(2) 287297.

Raman H, Gosal SS, Brar DS, 1992. Plant regeneration from callus cultures of Citrus limon and $C$. jambhiri. - Crop. Impr 19(2), 100-103.

Rani G, Singh B, Sharma S, Rehan L, Zaidi AA, Nagpal A, Virk GS , 2004. Micropropagation of Kinnow (Citrus nobilis $x$ Citrus deliciosa) through nodal segments. Jlnd Bot Soc 83:26-29.
Ramdan R, Handaji N, Beyahia H. and Ibriz M, 2014. Influence of growth regulators on callus induction from embryos of five citrus rootstocks. Journal of Applied Biosciences 73: 5959- 5965.

Sabharwal PS, 1963. in vitro culture of ovule, nucelli and embro of citrus reticulata var 'Nagpuris wingle.Plantt issue and organ culture. International society of plant morphology. Pp:255274.

Shrivastava S, Chawla HS, 2001. Synergistic effect of growth regulators and glutamine on regeneration response in high yielding cultivars of wheat (Triticum aestivum L.). Ind. J. of Gene and Plant Breed 61:12.

Singh B, Sharma S, Rani G, Zaidi AA, Virk GS, Nagpal A ,2006. In vitro flowering in embryogenic cultures of kinnow mandarin (Citrus nobilis Lour $\times C$. deliciosa Tenora). Afr J Biotechnol 5:1470-1474.

Sarker KK, Kabir AH, Sharmin SA, Nasrin Z, Alam MF, 2007. Improved somatic embryogenesis using LAsparaginein wheat (Triticum aestivum L.). original scientific papers 631.547.1.(045) $=862$.

Starrantino A, Licretti S, Russo G, Raciti M, Recupero RG , 1992.Embryogenus callus formation, protoplast regeneration and somatic fusion of different Citrus species. VII International Citrus Congress.

Savita, Vijay, Virk GS. and Avinash N, 2010. Effect of Explant Type and Different Plant Growth Regulators on Callus Induction and Plantlet Regeneration in Citrus jambhiri Lush - Environ. We Int. J. Sci. Tech., 5, 97-106.

Tang H, Ren Z. and Krczal G, 2000. Somatic embryogenesis and organogenesis from immature embryo cotyledons of three sour cherry cultivars (Prunus cerasus L.). Sci Hortic (Amsterdam), 83: 109-126.

Tao H, Shaolin P, Gaofeng D, Lanying Z, Gengguang L, 2002. Plant regeneration from leaf-derived callus in Citrus grandis (pummelo): Effects of auxins in callus induction medium. Plant Cell Tissue Org Cult 69:141-146.

Tao H, Shaolin P, Gaofeng D, Lanying Z, Gengguang L, 2002. Plant regeneration from leaf-derived callus in Citrus grandis (pummelo): Effects of auxins in callus induction medium. Plant Cell Tissue Org Cult 69:141-146. 
Usman M, Muhammad S, Fatima B, 2005. In vitro multiple shoot induction from nodal explants of Citrus cultivars. J Cent Europ Agric 6:435-442.

Vardi A et Spiegel-Roy P, 1982. Plant Regeneration From Citrus Protoplasts: Variability In Methodological Requirements Among Cultivars And Species. Theor. Appl. Genet.l 62: 171-176.
Vardi A, Bleichman S et Aviv D, 1990.Genetic Transformation of Citrus Protoplasts and Regeneration of Transgenic Plants .

Vasudevan A, Selveraj N, Ganapathi A, Kasthurirengan, Anbazhagan RV, Manickavasagam M (2004). Glutamine: a suitable nitrogen source for enhanced shoot multiplication in Cucumis sativus L. Biol. Plant 48(1):125-128. 